4th ISIS Conference Monte Carlo, Principality of Monaco, June 25-27, 1992

Session on: The Management of Stress: Psychological v. Biological Approaches

\title{
EFFECTIVE MANAGEMENT OF LIFE STRESS: THE RESOURCE-CONGRUENCE MODEL
}

\author{
PAUL T. P. WONG, PhD CPsych \\ Trent University \& University of Toronto, Canada
}

\section{SUMMARY}

This article questions traditional conceptions of stress and coping and presents a more comprehensive analysis of stress management. Sources of stress are expanded to include various intrapsychic and interpersonal stressors. The evolution of coping strategies is described, culminating in proactive, collective, creative, existential and spiritual coping. The resource-congruence model posits that coping is effective to the extent that appropriate resources are available and congruent coping strategies are employed. The model emphasizes the importance of developing resources in anticipation of exigencies, and the need for acquiring cultural knowledge as to what coping strategies are suitable for a given stressor.

KEY WORDS-Stress management, personal resources, social support, hardiness, culture, adaptation, stress.

No one can claim immunity from life's problems, but everyone can learn how to be more effective in coping.

There are vast individual differences in how we react to life stress. While some are vulnerable, and become easily overwhelmed by stress, others are very resilient. Why do similar misfortunes lead one person to distress and another person to success? What accounts for these differential effects of stress? What are the mediating variables? What are the mechanisms for effective coping?

Space does not permit a thorough treatment of these complex issues. This article only shows that these questions can be answered from the perspective of a resource-congruence model.

*Address for correspondence: Dr Paul T. P. Wong, 1449 Champlain Drive, Peterborough, ON K9L 1N3, Canada. Tel: (705) 742-8867. Fax: (705) 749-1580.

$0748-8386 / 931010051-10510.00$

(C) 1993 by John Wiley \& Sons, Ltd.

\section{ILLUSTRATIVE CASE STUDY}

Faye was a young woman with many psychological and physical problems. She suffered from epilepsy, insomnia, hypertension, frequent migraine headaches and was hard of hearing. She complained about the side-effects of the anticonvulsion drug she was taking. She was unhappy about her work in a nursing home: the workload was heavy, her supervisor was very demanding, and some of her coworkers were not very nice to her. To make things worse, she had to live with and care for an aging relative, who often interrupted her sleep with his groaning and demands for attention. She had not yet got over the hurt of having been dumped by her boyfriend; her feelings of loneliness were made more unbearable by her painful memories.

Yet, there was some strength in her - she was a fighter, and she had ambitions. In spite of her

Received 15 August 1992 Accepled 3 Sepiember 1992 
brutal schedule, she managed to take evening courses so that she could get a better job. Unfortunately, her physical limitations and her lack of formal education meant that she had no real prospects for a career move. Her many unfulfilled expectations only added to her sense of frustration and despair. Life to her was full of struggles and pain, but devoid of meaning.

When she first came to see me, she had large blotches of rash all over her face and neck; she was depressed and she talked about suicide. Over a period of several months of counselling, her condition improved somewhat. A new prescription reduced the side-effects of medication. Her aging relative was hospitalized, thus providing some relief to her burden of caregiving. She got involved in a Christian fellowship that gave her much-needed social and spiritual support. She also developed a more positive attitude towards work and more realistic career expectations. Her need for love and intimacy remained unfulfilied, and she was still worried about grand mal attack, but she had learned how to manage most of her psychological and physical problems and no longer experienced frequent bouts of depression.

\section{THE DIAGNOSIS OF LIFE STRESS}

The first step towards effective coping is to identify the sources of stress. We reed to know what the problems are and where they come from. Since stress is originally an engineering concept, referring to the amount of external pressure acting upon an object, traditional stress research tends to focus on noxious stimulation, aversive situations or outside pressures. We tend to think of stress as something that life throws at us. For example, Holmes and Rahe's social readjustment rating scale $e^{1}$ basically focuses on the life events that happen to us, such as death of spouse, got fired at work, and changes in financial state or living conditions. If we use this scale to assess Faye's life stress, only one item applies to her, which is 'irouble with boss'. The daily hassies scale developed by Kanner et al. ${ }^{2}$ is not much help either, because it only covers the mundane types of frustration and irritations of everyday living, such as interruptions.

The Wheatley Stress Profile ${ }^{3}$ is a better diagnostic tool, because it quantifies stress in nine areas, such as social habits, social relationships, life events. Wheatley has provided evidence based on 300 patients that the WPS measured stress-related symptoms and was sensitive to the results of inter- vention. Although the WPS is clinically useful, it still falls short of being a comprehensive measure of life stress.

A more complete description of life stress is shown in Fig. 1. The various circles represent the different domains where we are likely to encounter stress.

\section{DOMAINS OF STRESS}

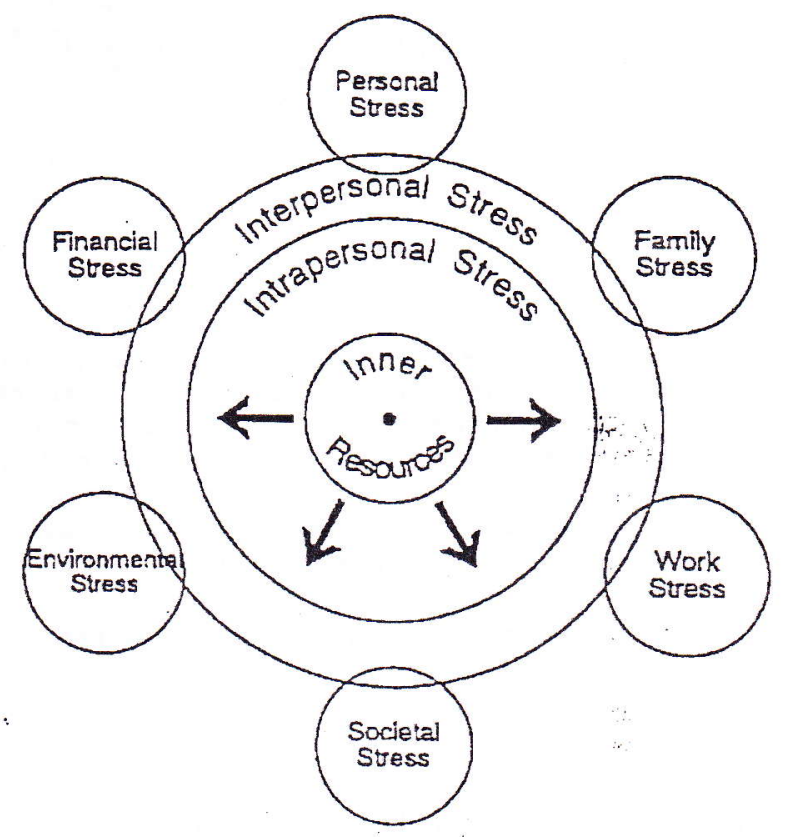

Fig. 1-Domains of stress in everyday life

The innermost circle represents the inner core of our being, call it ego strength, mental toughness, psychic energy or inner resources. This is where we fall back on in coping with the crises of life. Stress resistance depends on having a vast inner reserve, as depicted in Fig. 1. When inner resources dwindle to a tiny dot, the individual will become very vulnerable to various stress-related disorders, such as reactive depression and anxiety.

Next, notice the large inner circle of intrapersonal stress. Most of our pressures and demands come from within. This circie is the centrifugal force that affects all areas of our lives. If we are not at peace with ourselves, our inner tumoil is likely to spill over, giving rise to self-destructive actions and poisoning interpersonal relationships.

Most of Faye's problems, such as unfulfilled 
expectations and needs, perceived meaninglessness of life and painful memories of the breakup with boyfriend, fall into this category. Because of the deeply entrenched environmental bias of mainstream psychology; these inner stressors have been largely ignored by researchers.

The circle of interpersonal stress interacts with specific life domains. Since we have to engage the social world in most of our activities, our interactions with others and our evaluation of interpersonal relationships have a pervasive effect on how we feel. Most problems are people problems. Just thinking about how to avoid conflict with abrasive and aggressive individuals is already a drain on our mental energy. How wonderful life would be if everyone was reasonable, understanding and kind, and we treated each other with dignity and respect. Unfortunately, the reality is that we often have to deal with toxic people and work with diffcult individuals. Conflict and mistrust are fuelled by competition. Selfishness and ruthlessness have become prerequisites to survival. Much energy is consumed in turf fighting and self-defence.

\section{Personal stress}

Personal stress refers to what we do and what happens to us as individuals when we are not performing certain well-prescribed social roles such as parent, husband or employee. It encompasses such daily hassles as poor health, bad habits, sexual difficulties, boredom and the lack of recreational opportunities. It also includes life transitions such as menopause, retirement and aging. Cognitivel emotional problems and relationship difficulties are excluded here because they are considered in their own right under intrapersonal and interpersonal stress, respectively.

\section{Family stress}

Family stress encompasses all the difficulties of keeping the family together. Household chores, marital problems, sibling rivalry, intergenerational conflicts, the trial of living with adolescents, illness and death in the family are some of the common problems. Alcoholism, family violence, sexual abuse and divorce have become epidemic in recent years.

\section{Work stress}

Work stress typically includes heary workload, lack of control, role ambiguity and role confilct.
In a recession, job insecurity, performance evaluation, office politics, downsizing and ruthless cutbacks and incompetent and unfair management have become the major sources of stress for workers.

\section{Socielal stress}

Societal stress refers to problems experienced by large segments of a society or community, such as economic depression, poverty, drug abuse, racial tension and discrimination. These tend to be history-graded events.

\section{Environmental stress}

Environmental stress includes both living conditions and natural environments. Air and water pollution, inciement weather, crime-infested neighbourhoods, crowding and high noise level are all examples of environmental stress.

\section{Financial stress}

Financial stress is self-explanatory. When your debt load is greater than your assets, or when you cannot pay your bills, then you are in financial trouble. However, when you cannot collect what others owe you it can be equally stressful.

\section{THE TEMPORAL DIMENSION OF INTRAPERSONAL STRESS}

Intrapersonal stress deserves closer examination not only because of its importance, but also because of its past neglect by stress researchers. Fig. 2 shows the various types of stressors along the temporal dimension.

Many of our problems have their roots in the past. The hurts and pains of growing up in a dysfunctioning family; the scars of childhood sexual abuse, unresolved conflicts with parents ... these demons from the past can haunt us for years. Shame and guilt are the shackles that chain us to the past. Repressed memories and bottled-up emotions are a perpetual source of tension within us. Both psychoanalysis and more cognitively based reminiscence therapy are aimed at dealing with unresolved conflicts and healing painful memories.

With respect to present conditions, again we are faced with a host of inner stressors. Existential crisis is concemed with both meaning in life (provisional meaning) and meaning of life (higher, uitimate meaning). Related to such concerns are the philosophical issues of suffering: why do I suffer 


\section{Intrapersonal Stress}

\begin{tabular}{|c|c|c|}
\hline Past & Present & Future \\
\hline Life events & Existential crisis & Anticipatory Stress \\
\hline $\begin{array}{l}\text { Childhood } \\
\text { traumas }\end{array}$ & Emotional reactivity & Fear of uncertainty \\
\hline \multirow[t]{2}{*}{$\begin{array}{l}\text { Unresolved } \\
\text { confiicts }\end{array}$} & Interpretative stress & Fear of aging \\
\hline & Frustration & Fear of dying \\
\hline
\end{tabular}

Fig. 2-Types of intrapersonal stressors along the temporal dimension

from epilepsy? Why me? Why this? It also deals with the larger issues of identity crisis: what is life all about? Have I wasted my life? There's got to be more to life than work and money. An increasing number of middle-aged people have sought professional help because of existential crisis. Frankl's logotherapy has given existential anxiety the recognition and attention it deserves.

Negative affectivity also predisposes us to the experience of distress $s^{3}$. We may have such a high level of emotional reactivity that we are constantly disturbed and pained, as if all our nerve endings have been exposed.

To add to our misery, we may have the paranoic tendency of perceiving danger lurking round every corner. Mistrust and fear are never too far from our consciousness. We are convinced that being paranoic does not mean that people are not out to get us. Misattributions enable us to perceive a hidden agenda in every utterance, and malice behind every smile.

Life can be unbearable when most of our expectations remain unfulfilled and all our cherished dreams have been shattered. Frustration and disappointment eventually lead to bitterness, hostility and despair. No matter where the blame is laid, the perception of self as a failure exacts an enormous price.

The litany of our inner troubles would not be complete without including all sorts of foreboding. It has been said that fear of failure is worse than failure itself. Similariy, worries about future misfortunes, whether real or imagined, can be more stressful than actual disasters. Fear of aging and dying may be pushed beneath the surface of our consciousness; nevertheless, it is always there to harass us until we leam to come to terms with this ultimate truth of life.

When the psychic system is full of tension and conflicts, one does not need any outside pressure to feel anxious and stressed out. Our inner tension can spill out and create all sorts of problems, ranging from constant squabbling to violent acts. When the inner pressure reaches a certain point, it can explode without any provocation. Therefore, in the diagnosis of life stress, we need to pay particular attention to internal stressors.

\section{DIMENSIONS OF LIFE STRESS}

The aforementioned domains of stress serve as a useful guide during interviews in which we can explore and map out the various stressors experienced by the client. To know where most of the troubles come from is essential in planning intervention.

\section{Multifaceted Stress Profile}

Another approach to stress management is to focus on qualitatively different dimensions. In connection with our research on successful aging, Gary Reker and I have developed the Multifaceted Stress Profile (MSF), a questionnaire that measures both the presence and impact of potential stressors within each dimension. The six major dimension are shown in Fig. 3. 


\title{
DIMENSIONS OF STRESS
}

\author{
1. LIFE-EVENT STAESS \\ MANOR EVENTS OR LIFE CHANGES \\ Examples: Death of spouse, break-up of an important relationship \\ 2. EVERYOAY STRESS \\ FREQUENT LIVNG EXPERIENCES \\ Examples: Arguments, internuptions \\ 3. ANMIIPATORY STAESS \\ CONCERNS OR WORAIES ABOUT FUTURE EVENTS \\ Examples: An impending deadline, the prospect of being laid off \\ 4. INTERPRETATIVE STRESS \\ STRESS THAT DERIVES FROM OUR INTERPRETATION OF EVENTS \\ OR CONDITIONS OF EXSTENCE \\ Examples: Malicious intent in others, meaninglessness in life \\ 5. SELF-PEAPETUATING EMOTONAL STAESS \\ AN EMOTIONAL REACTION THAT HAS BECOME SO EXAGGERATED \\ AND PERSISTENT THAT IT TAKES ON A LIFE OF ITS OWN \\ Examples: Various kinds of phobia, pathological griel

\section{SOCIETAL STRESS}

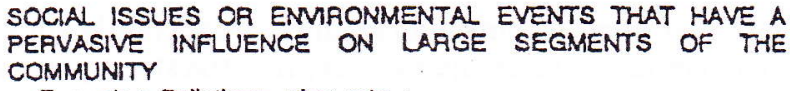

Fig. 3-Dimensions of life stress as measured by the Multifaceted Stress Profle (MSF)

The first three dimensions encompass past, present and future orientations, respectively. Note that the life-event stress inciudes childhood traumas, as long as they still have some impact on the individual. The forth and fifth dimensions focus on intrapersonal stress. The last dimension has to do with the larger socioenvironmental context. Our preliminary data analysis has shown that interpretative and self-perpetuating emotional stress most clearly differentiates between successful and unsuccessful agers, thus implicating the adverse effects of intrapersonal stress on adjustment to aging.

\section{A cognitive-relational model}

Having deternined the sources of stress, we are now ready to examine the stress process and the mechanisms of coping. According to Lazarus and Folkman", stress is a "particular relationship between the person and the environment that is appraised by the person as taxing or exceeding his or her resources and endangering his or her wellbeing' (p. 19).

Since stress does not always originate from the environment, Wong has redefined stress as a "problematic internal or external condition that creates tension/upset in the individual and calls for some form of coping' (p. 70); such conditions stem from the individual's appraisal of an imbalance between personal resources and demands as well as a perceived threat to his/her well-being. To put it simply, stress is a problematic condition resulting from the appraisal of an imbalance between demands and resources and calls for efforts to restore the balance.

According to this cognitive-relational view, stress is an interactive, dynamic process that is triggered by appraisal of the presence of stressor(s), mediated by coping, and results in certain outcomes. Whenever the person perceives that the demand taxes or exceeds available resources, he/she will experience some tension and the need to do 


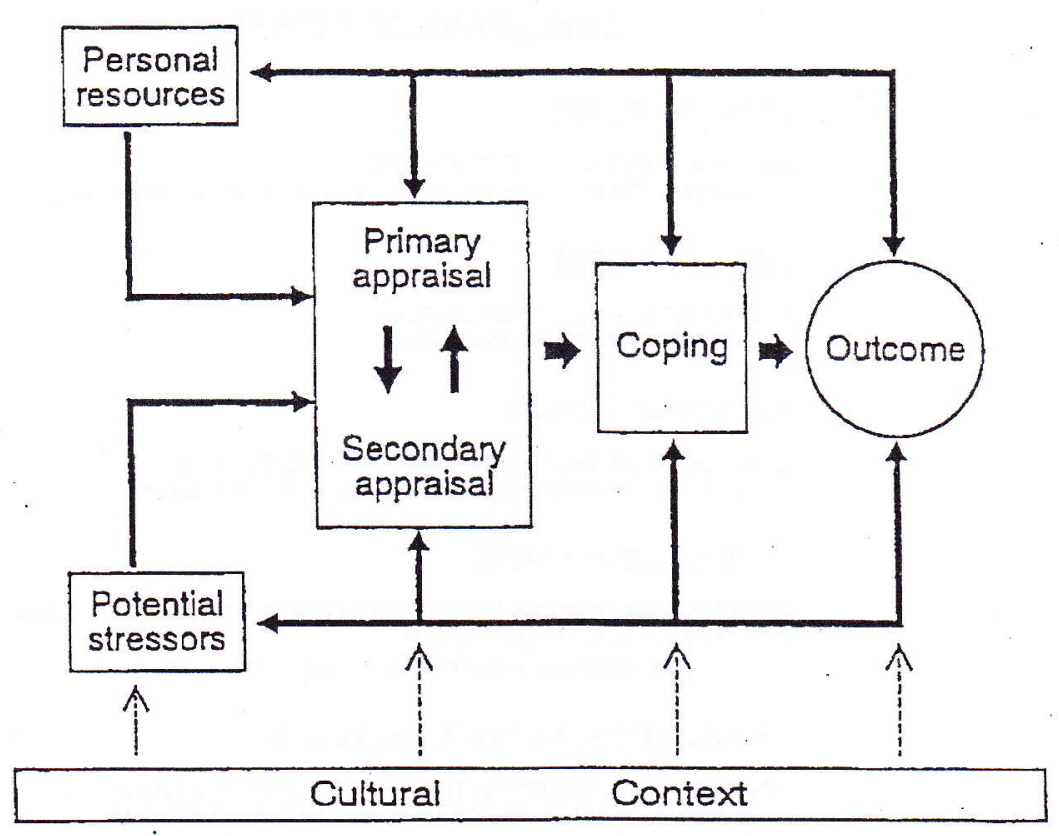

Fig. 4-A schematic presentation of the cognitive-relational model of stress

something about the problem. Coping is an attempt to resolve the problem and restore the balance; it consists of a combination of behavioural, cognitive, psychodynamic and physiological responses to remove the tension or threat. Fig. 4 presents a schematic view of this process.

\section{Appraisal}

You can't fix the problem if you don't know what it is. Therefore, the first step in effective coping is appraisal. The importance of cognitive appraisal in the stress process has gained wide acceptance. Appraisal determines whether one experiences stress and how one copes with it.

Primary appraisal is concemed with assessing whether we have a problem on hand and how serjous it is. It asks such questions as: Am I in trouble? Is the situation hamful? Is the threat really serious? Is it central to my well-being? Answers to these questions would depend on input from secondary appraisal. Primary appraisal functions as an executive who decides whether a stressful condition does exist and some form of coping is needed.

Secondary appraisal processes such relevant information as: What is troubling me? What kind : of problem is it? What can be done about it? Is it within my control? This is an ongoing process, constantly monitoring the various components in the stress process and feeding the results to primary appraisal.

\section{Coping strategies}

Just as we need to know what the stressors are, so we need to know what kinds of coping strategies are at our disposal. This article is primarily concerned with psychological rather than physiological and endocrine responses. There has been an evolution of psychological coping in terms of conceptual development, and progression towards greater differentiation, as depicted in Fig. 5.

Sir Waiter Cannon's discovery of instinctual coping patterns (ie the fight-or-flight reaction and surrender) has become part of our cultural knowled ge. Such coping patterns are prevalent in the animal kingdom. Individuals who depend primarily on these primitive coping patterns have very little chance of success in adapting to today's complex society: we cannot punch out everyone who gives us trouble; nor can we constantly seek escape in alcohol and drugs.

Freud's conception of various defence mechanisms to cope with threats to ego integrity has also gained wide acceptance. Concepts such as 


\section{The Evolution of Coping}

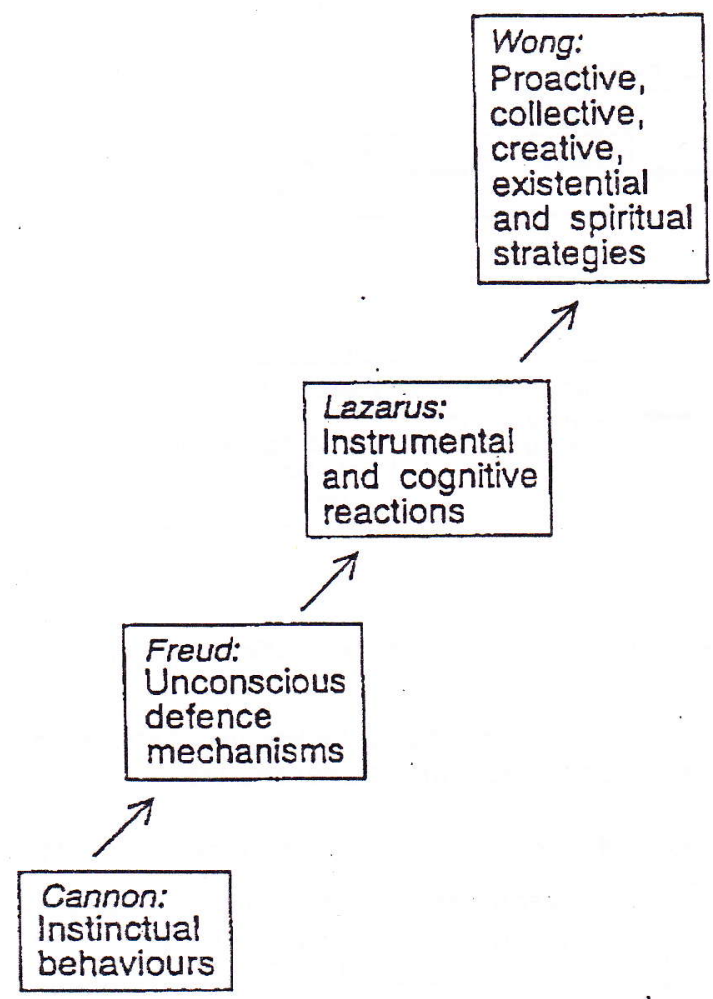

Fig. 5-The evolution of coping strategies

repression, rationalization and denial have become household words. Most of these mechanisms are assumed to be innately determined and operate unconsciously. Freud is primarily concerned with how the human mind defends itself against neurotic and moral anxiety, but he has little to say about how to reduce other types of stress.

The measurement of cognitive and behavioural coping developed by Folkman and Lazarus ${ }^{8}$ marks an important step forward because it emphasizes learned rather than innate mechanisms. Problemfocused coping consists of various learned instrumental strategies. Emotion-focused coping includes some Freud's defence mechanisms and other types of cognitive strategies.

\section{CREATIVE COPING}

More recently, Wong and his associates ${ }^{9}$ have developed a coping measure that encompasses preventive, self-restructuring, existential and spiritual strategies. These are uniquely human adaptive responses, because they depend on the human capacities for symbolism, projecting into the future, selfreflection and spiritual exercise. We may also add collective and creative coping to this list. Collective is more than receiving social support; it means the concerted effort involving all members of a group to tackle the same problem. For example, all family members rally together to cope with the stress of caring for a terminally ill parent. Creative coping refers to finding novel solutions to old problems; it is built on past leaming but it is generated by imagination and exploration of new avenues.

\section{Cultural context}

The sociocultural context of stress plays an important role in effective coping. Culturally based expectations influence what is appraised as stressful. The cultural milieu in which one was socialized predisposes one to react to stress in a certain fashion. More importantly, cultural knowledge is needed to determine what coping behaviour is appropriate for a given situation. Finally, ethnicity can be both a resource for coping and an additional source of stress. A full discussion of cultural issues in adaptation can be found in Wong and Ujimoto. ${ }^{10}$

\section{A resource-congruence model of effective coping}

The model posits that sufficient resources and appropriate utilization of these resources are essential to effective coping. Conversely, deficient resources and/or gross deviations from congruence would lead to ineffectual coping and make the individual vulnerable to stress-related disorders. Fig. 6 is a schematic presentation of the resourcescongruence model of effective coping.

An important feature of this model is the emphasis on proactive measures. If the individual constantly develops a variety of resources, and avoids unnecessary risks, then she/he will reduce the likelihood of stress encounters.

Reactive coping begins as soon as a problematic condition is declared by primary appraisal. At this stage, two types of congruence are important to effective coping. First, appraisal should accurately reflect reality and be based on an objective, rational assessment of the demands and available resources. Secondly, the strategies selected need to be congruent with the nature of the stressor.

Adequate resources and congruent coping would eventually lead to a reduction of stress. One is able to relax and conserve personal resources 


\section{A Resource-congruence Model of Effective Adaptation}

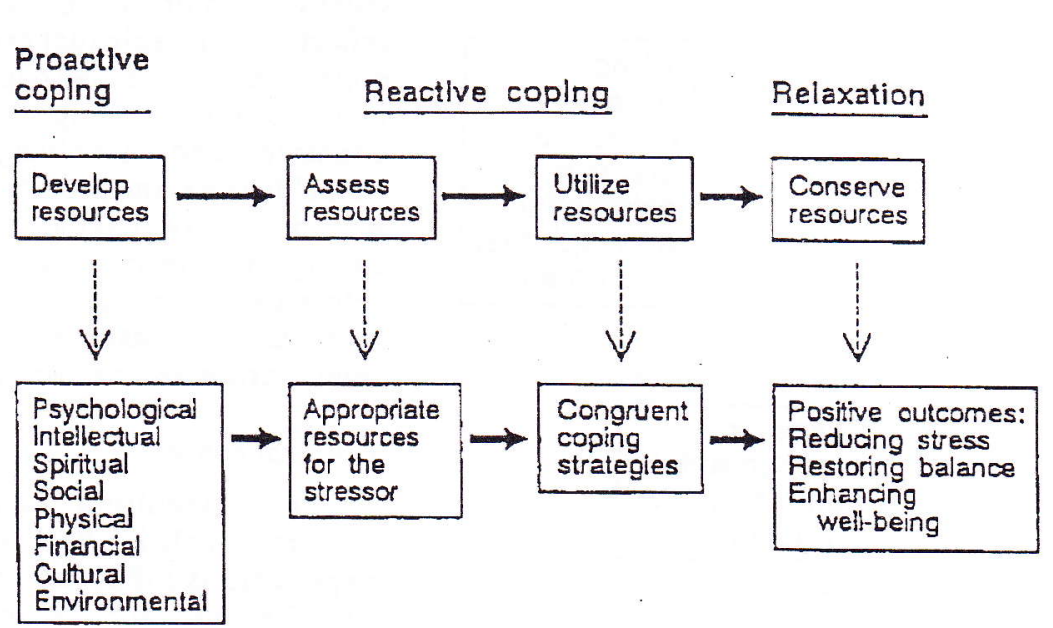

Fig. $6-$ A schmatic presentation of the resource-congruence model of effective coping

when some degree of success in adaption is achieved. This cycle may be repeated many times in the case of a very difficult or chronic problem.

Effective coping is flexible, creative and resourceful in that good use is made of available resources. The following are some indices of effective coping: efficiency in terms of expenditure of energy and resources; efficacy in achieving the desired goal of removing stress and restoring balance; and personal growth in terms of enhanced competence, self-esteem and well-being. Thus, successful coping yields both short-term and long-term benefits.

\section{Congruent coping}

Secondary appraisal is involved in assessing the nature of the stressor and selecting appropriate strategies on the basis of available resources and cultural knowledge. We have already denonstrated that individuals do engage in such assessments and that there is a linkage between secondary appraisal and coping strategies. ${ }^{11.12}$ The matching between various types of stressors and coping strategies is illustrated in Fig. 7.

Congruence is unlikely to be achieved when one reacts to stress emotionally, instinctively or habitually. The best way to achieve matching is to detach oneself from the siruation and ask: What would an ideal coper do in this situation? What would be the most logical answer to this problem?
Therefore, one of the lessons of stress management is the need for rational analysis.

\section{A resource-deficit model of mental health}

Resources are the devices and means of supply that can be drawn on in times of need. Most of the resources listed in Fig. 6 can be considered as personal to the extent that they can be developed, possessed and utilized by the individual. The importance of personal resources in coping has gained increasing attention. ${ }^{13.14}$ This section will focus on psychological resources.

The traditional approach to resilience is to identify traits that are resistant to stress. For example, Kobasa ${ }^{15}$ emphasizes the following three characteristics of a hardy personality: (1) the belief that they can control or influence their life events; (2) the ability to feel deeply involved and committed in life activities; and (3) the optimistic anticipation to change.

More recent research is concerned with attitudes and cognitive systerns that contribute to resilience. Considerable research has been done on the bereficial effects of control beliefs ${ }^{16}$ and optimism. ${ }^{17.18}$ Personal meaning has also been identified as a major psychological resource. ${ }^{19-21}$

It is important to keep in mind that psychological resources and defficits are not opposite poles of the same continum, such that increase in the positive would mean an automatic reduction of the negative. We have obtained preliminary evidence that 


\section{- Congruent Coping Strategies}

1) Controllable by seif<smiles>[SiH3]</smiles>

2) Controllable by others

3) Attitudinal problem

4) Emotional problem

5) Philosophical problem
Self-reliance or problem-focused coping

Social support or dependence on others

Cognitive restructuring

Palliative coping

Existential coping

Fig. 7-Types of stressors and congruent coping strategies

resources and deficits often coexist in a state of dynamic tension as depicted by the Chinese symbol of ying-yang in Fig. 8.

\section{PSYCHOLOGICAL RESOURCES AND DEFICITS}

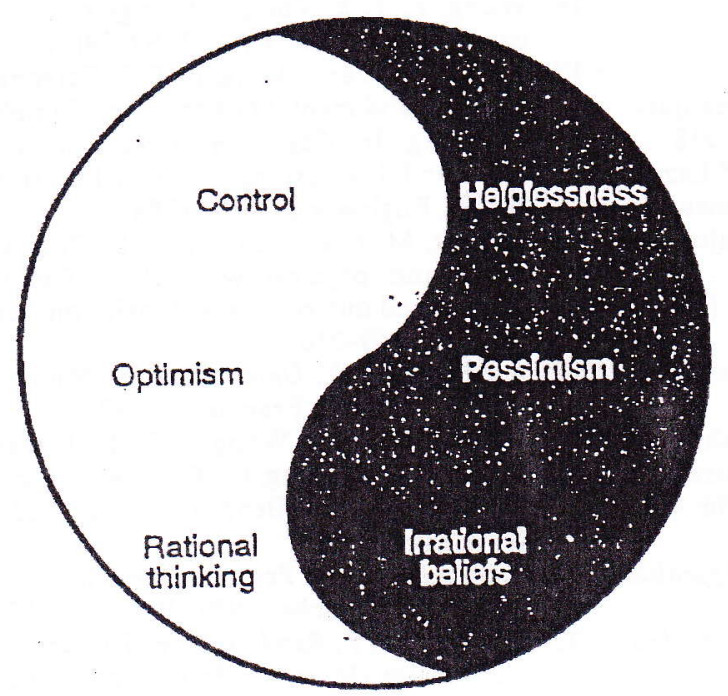

Fig. 8-A symbolic presentation of psychological resources and deficits

The dark side includes everything negative feelings of helplessness and meaninglessness, pes- simistic views, self-deprecation, perfectionistic beliefs, painful memories, and destructive impulses. All these deficits sap our energies, make us feel bad and reduce our effectiveness in coping. Deficits represent a parallel cognitive-emotional system that competes with psychological resources. Thus, optimism and self-doubt may be waging a constant tug-of-war, while one's sense of mastery is trying desperately to ward off feelings of powerlessness. The net psychological resources available to the person depend not on the actual amount of resources possessed, but on the balance between resources and deficits.

In view of the above analysis, to enhance stress resistance and improve mental health requires that we cultivate psychological resources and reduce deficits at the same time. To increase resources, we need to foster a sense of mastery while recognizing external constraints and internal limitations; we need to explore sources of personal meaning: we can also cultivate our capacity for dreaming and hoping. In dealing with the deficits, we need to work on personal life history and replace irrationa! beliefs with more adaptive schemas ${ }^{23}$; we need to identify the character flaw that frequently defeats the individual's best intentions and efforts.

\section{CONCLUSIONS}

The resource-congruence model provides a novel and comprehensive approach to stress management. It goes beyond traditional concerns with reactive coping and emphasizes the genius of proac- 
tive measures. Effective stress management has to be better than merely putting out fires; it requires a new vision and a new approach to resource development that would minimize the need to put out fires.

Another contribution of the model is that it recognizes the vital role of cultural krowledge and rational analysis in achieving congruence. The ethnic background of the client and the cultural context of stress need to be taken into account in interventions. Further, the cognitive skills of realistic appraisal and selecting appropriate strategies can be acquired.

Finally, the heuristic values of the model needs to be mentioned. It has greatly expanded our vista of resilience research. Hardiness is no longer a limited set of personality traits but a long list of personal resources that can be cultivated and acquired. We can now systematically investigate how these resources operate singly and in different combinations to enhance resistance to various types of stressors. We can also study what kinds of resources are most importantiy involved in resistance to reactive depression. The concept of paraliel cognitive-emotive systems is also a fertile ground for research on the interactions of psychological resources and deficits and their effects on memory, affect and behaviour.

\section{REFERENCES}

1. Holmes, T. H. and Rahe, R. H. The social readjustment scale. J. Psychosom. Res. 1967; 11: 203-218.

2. Kanner, A. D., Coyne, J. C, Schaefer, C. and Lazarus, R.S. Comparison of two modes of stress measure ment: Daily hassles and uplifts versus major life events. J. Behav. Med. 1981; 4: 1-39.

3. Wheatley, D. The Wheatley Stress Profile (WSP). Brit. J. Psychior. 1990: 156, 685-688.

4. Wheatley, D. Assessment of stress: The Stress Profile. Siress Med. 1993. In Press.

5. Watson, D. and Pennebaker, J. W. Health complaints, stress, and distress: Exploring the central role of negative affectivity. Psychol. Rev. 1989; 96: 465490.

6. Lazarus, R. S. and Folkman, S. Stress, Appraisal and Coping. Springer, New York, 1984.

7. Wong, P. T. P. Measuring life stress. Siress Med. 1990; 6: $59-70$.
8. Folkman, S. and Lazarus, R. S. An analysis of coping in a middle-aged community sample. $J$. Health Soc. Behav. 1980; 22: 457-459.

9. Wong, P. T. P., Reker, G. T. and Peacock, E. J. The Revised Coping Inventory. Unpublished manuscript, Trent University, 1987.

10. Wong, P.T. P. and Ujimoto, K. V. The Asian American elderly: Their stress, coping and well-being. In: Handbook of Asian American Psychology. Lee, L. D. and Zane, N. (Eds). Sage, Newbury Park, CA, in press.

11. Peacock, E. J. and Wong, P. T.P. The Stress A ppraisal Measure (SAM): A multidimensional approach to cognitive appraisal. Siress Med. 1990; 6: $227-$ 236.

12. Peacock, E. J., Wong, P. T. P. and Reker, G. T. Relations between appraisal and coping schernas: Support for the congruence model. Can. J. Behav. Sci., in press.

13. Holahan, C. J. and Moos, R. H. Life stressors, personal and social resources, and depression: $A$ 4-year structural model. J. Abnormol Psychol. 1991; 100: $31-38$.

14. Moos, R. H. and Billings, A. G. Conceptualizing and measuring coping resources and processes. In: Hondbook of Stress: Theorenical and Clinical Aspects. Goldberger, L. and Breznitz, s. (Eds). Free Press, New York, 1982, pp. 212-230.

15. Kobasa, S. C. Stressful life events, personality and health: An inquiry into hardiness. J. Pers. Soc. Psychol. 1979; 37: 1-11.

16. Wong, P. T. P. The psychology of control (Special issue). Can. J. Behav. Sci. 1992; 24(2).

17. Reker, G. T. and Wong, P. T. P. Personal optimism, physical and mental health: The triumph of successful aging. In: Cognition. Stress and Aging. Birren, J. E. and Livingston, J. (Eds). Prentice-Hall, New Jersey, Englewood Cliffs, 1984.

18. Scheier, M. F. and Carver, C. S. Dispositional optimism and physical well-being: The infuence of generalized outcome expectancies on health. J. Pers. 1987; 55: 169-210.

19. Antonovsky. A. Unravelling the Mystery of Healih, Jossey-Bass, San Francisco, 1987.

20. Reker, G. T. and Wong, P. T.P. Towards a theory of personal meaning. In: Emergen Theories of Aging. Birren, J. E. and Bengtson, V. L. (Eds). Springer. New York, 1988.

21. Wong, P. T. P. Personal meaning and successful aging. Con. Psychol. 1989; 30(3): 516-525.

22. Wong, P. T. P. Reminiscence: Therapy und Resureh. Cambridge University Press, New York, in press. 